NOTAS

\title{
EL PRINCIPIO DE LA HIPÓTESIS MÁS DIFÍCIL
}

Agustín Segui ${ }^{*}$

Las hipótesis son enunciados que se aceptan sin prueba experimental. Por tanto, como ya lo indicó Aristóteles, no deben ser creídas necesariamente. Se las asume, entonces, no por lo que ellas afirmen (de hecho, en contra de las definiciones, las hipótesis no afirman ni niegan nada), sino por las consecuencias que de ellas se deducen. Ese conjunto de hipótesis y conclusiones constituye, así, un andamiaje o (modificando la metáfora arquitectónica) un fundamento sumamente útil en la edificación de teorías científicas.

Claro está que ese fundamento resultará tanto más provechoso cuanto más sólido sea, ya se persiga con él la explicación causal de enunciados

* Universität des Saarlandes. previamente formulados, ya se intente con su ayuda predecir enunciados nuevos. Precisamente en este contexto, es decir, en la discusión acerca de qué deben ser y qué deben evitar las hipótesis para resultar aprovechables, hay un principio que se reitera varias veces en la historia del pensamiento sin que, a mi entender, haya sido formulado por algún autor con el necesario grado de generalidad. $\mathrm{Me}$ refiero al principio que sirve de título al presente trabajo. Puesto un científico ante la alternativa de elegir, como punto de partida, una hipótesis sencilla o una difícil, la decisión deberá basarse en una serie de criterios que es imposible discutir aquí y que depende al menos en parte de la ciencia en cuestión pero que, en ningún 
NOTAS

caso, puede incluir el del menor esfuerzo.

Comencemos con un ejemplo: en lingüística existe una vieja discusión acerca de si realmente es posible traducir o no de un lenguaje natural a otro. Hay quienes niegan ambas tesis extremas, tanto la de la intraducibilidad más o menos absoluta, representada por la llamada 'hipótesis Whorf-Sapir', como la de una traducibilidad sin barreras. ${ }^{\prime}$ Otros lingüistas atacan duramente el 'principio de no traducibilidad"2 como algo prácticamente superado; de hecho, incluso los únicos partidarios actuales de la hipótesis Whorf-Sapir citados por este último autor, ${ }^{3}$ a saber, Kluckhohn/ Leighton, en la 'revised edition' que he consultado, ya no presentan ninguna formulación extrema de dicho principio. $^{4}$

${ }^{1}$ Niega ambas posiciones, por ej., Koller: 6.1, postulando en 6.1.3 y 6.1.4 su propia tesis de una 'traducibilidad relativa', Werner Koller, Einführung in die Übersetzungswissenschaft, 1983, Heidelberg, Quelle und Meyer.

${ }^{2}$ Wolfram Wilss, Übersetzungswissenschaft. Probleme und Methoden, 1977, Stuttgart, Klett, p. 36-57.

${ }^{3}$ Ibid., p. 47.

${ }^{4}$ Clyde Kluckhohn/Dorothea Leighton, The Nahavo, 1962, revised edition, Garden City, N. Y., The Natural History Library, Anchor Books, Doubleday \& Company.
En favor de la posibilidad de traducir, sin embargo, habla también el argumento derivado del principio antedicho con el cual he titulado estas líneas. La formulación más rotunda que he encontrado del mismo, aunque referida solamente a la filosofía, es la siguiente: "En las cuestiones filosóficas [...] nada es simple. Toda solución fácil es una solución equivocada. Por lo general es una solución perezosa. Como el escepticismo, que nos libera de toda obligación de realizar investigaciones laboriosas, puesto que, según él, no hay nada que investigar." E1 principio epistemológico en cuestión sostiene, entonces, que hay que dar prioridad a la hipótesis difícil, en vez de dejarse llevar por la más simple; para un pensador de garra, la hipótesis más tentadora será siempre la más exigente.

La formulación precedente es ya una generalización válida, pero reducida a la filosofia, de lo que Kant había ya aplicado a un campo de la misma: en su "Metodología trascendental", este gran maestro de generaciones advierte que sería insensato aplicar una 'hipótesis trascendental', la cual no es más que 'una pura idea de la razón' (e.d. un producto pura-

${ }^{5}$ Joseph M. Bocheński, Wege zum philosophischen Denken, 1972, Friburgo, Herder, p. 45, cursivas mías. 
mente racional), al conocimiento de la naturaleza (e.d. al conocimiento de los fenómenos empíricos); sostiene que, en tal caso, cualquier hipótesis 'física', por descabellada que sea, resultará más tolerable que una 'hiperfísica' (e.d. metafísica). En efecto, sigue diciendo el filósofo, "sería propio de un principio de la razón perezosa (ignava ratio) dejar de lado de repente todas las causas cuya realidad objetiva (al menos en principio) puede llegar a conocerse mediante un prolongado recurso a la experiencia para, a cambio, buscar reposo en una simple idea que sea muy cómoda a la razón".

Ahora bien: todo esto no se aplica solamente a la filosofía. Tampoco a la traductología, que me ha servido de ejemplo para entrar en materia. Eso sí: ambos casos tienen algo en común; tanto en la traductología como en la teoría filosófica del conocimiento, la hipótesis primera debe ser la que afirme la posibilidad de algo, ya sea la de conocer o la de traducir. Sin embargo, históricamente se trata de la tesis más ingenua. Por no tener antítesis durante una larga etapa de la historia del pensamiento, incluso es dificil encontrar esa tesis formulada explícitamente; más bien se

${ }^{6}$ Immanuel Kant, Kritik der reinen Vernunft, Critica de la razón pura, B 801/A773, cursivas mías. trataba de un presupuesto implícito. Luego aparece un Descartes (o un Whorf, o quienes sean los que por primera vez pusieron seriamente en duda la posibilidad de conocer o traducir), y surge así una antítesis, la cual sostiene, al menos, la necesidad metodológica de criticar la certeza). A partir de ese momento se generaliza la suposición de que la antítesis crítica supera la tesis superficial (la duda metódica supera el realismo ingenuo, etc.). Ello es independiente de que, en el marco del mismo progreso, en un momento dado se supere la duda para reafirmar (pero esta vez con una base no ingenua) la posibilidad de conocer o traducir que había sido cuestionada. En gnoseología es el mismo Descartes quien se encarga de superar su propia duda. Ello equivale a decir que, con o sin superación de la duda, ésta es considerada, en la historia del problema, como una posición superior a la de la tesis inicialmenté presupuesta. $\mathrm{Si}$, por el contrario, he hecho mías las palabras de Bochenski que coloca la duda (o negación) radical en la posición inferior, es porque adjudico la posición superior no a la certeza inicial ingenua sino al intento de superar la duda. Podemos considerar fallida la respuesta concreta de Descartes a su propio cuestionamiento, pero lo indudable es que hay que seguir buscando respuestas en 


\section{NOTAS}

lugar de quedarse perezosamente con el escepticismo.

Esa pereza no ha sido rechazada sólo en los dos campos ya mencionados. Para la epistemología en general encontramos una estupenda formulación debida a la pluma de Einstein: "Es muy curioso lo que sucede con los trabajos científicos: a menudo nada tiene tanta importancia como notar dónde no merece la pena gastar tiempo y esfuerzo. Por otra parte, tampoco hay que perseguir las metas que sean fáciles de alcanzar. Hay que formarse un instinto que le permita a uno darse cuenta de lo que puede alcanzarse con el máximo esfuerzo." Con la segunda frase nos dice Einstein que no hay que hacer a un lado de entrada la 'hipótesis más difícil'; ésta, sin embargo -nos dice con la primera frase- puede resultar un fiasco, pero sólo un instinto certero puede evitarnos perder tiempo con ella sin hacernos reos de incuria.

La formulación siguiente, tomada de un gran epistemólogo, se mantiene todavía en un plano general y abstracto, aunque haciendo mención de una corriente filosófica concreta

${ }^{7}$ Carl Seelig: Albert Einstein-Eine dokumentarische Biographie, Zurich/ Stuttgart/Viena, 1954, p. 169 s., cit. en Johannes Wickert, Albert Einstein in Selbstzeugnissen und Bilddokumenten, 1977, Reinbek bei Hamburg, Rowohlt, p. 98 s., cursivas mías. (tan importante como la del escepticismo ya mencionado): se trata del platonismo, cuan seductor por ser en el fondo irrefutable: en efecto, ¿cómo queremos refutar la existencia de ese Mundo de las Ideas que, según Platón, fundamenta el conocimiento del mundo material? Piaget lo rechaza "en cuanto a las relaciones entre el platonismo y la construcción genética o histórica de las estructuras. Es cierto que la hipótesis platónica es irrefutable en el sentido de que, de una construcción, una vez efectuada, puede afirmarse siempre que, por ese hecho mismo, ha estado eternamente predeterminada en el mundo de los posibles, considerando a éste como un todo estático y acabado. Pero, como esta construcción constituía el único medio de acceso a un semejante universo de las ideas, se basta por sí misma sin que haya necesidad de hipostasiar su resultado". 8

Con las citas precedentes queda suficientemente aclarado el título del presente trabajo. Queda ahora por ver hasta qué punto la 'hipótesis más difícil' ha sido ya provechosa en la historia de las ciencias. Voy a limitarme a unos pocos ejemplos. Pensemos en la 'revolución copernicana':

${ }^{8}$ Jean Piaget, L'épistémologie génétique, 1972, París, PUF, p. 118, cfr. también p. 111 sobre biología. 
aceptar el geocentrismo era más fácil que probar el heliocentrismo..$^{9}$ En biología, el creacionismo es, como hipótesis, mucho más cómodo que el evolucionismo; de hecho, las palabras antes citadas de Kant se refieren a algo muy semejante: como ejemplo de 'hipótesis hiperfísica' menciona Kant expresamente el hecho de postular la existencia de Dios (literalmente: de 'un autor divino') para explicar algún fenómeno físico o la existencia misma del mundo físico. ${ }^{10}$ Otro tanto se aplica a los descubrimientos de Mendel y a sus consecuencias: la afirmación de que los factores innatos tienen más influencia sobre el comportamiento humano que lo aprendido despierta sospechas de racismo; se acepta la etología de Konrad Lorenz y la sociobiología de $\mathrm{O}$. Wilson mientras se las aplique más bien a los animales que al hombre; por lo demás, los procesos de aprendizaje son más fáciles de probar por experimentación que los procesos genéticamente determinados. Resulta curioso leer un libro de psicología ${ }^{11}$ en el que se sos-

${ }^{9}$ Sobre las inmensas dificultades teóricas que debió superar Kepler, cfr. Albert Einstein, Mein Weltbild, 1981, Frankfurt, Ullstein, $\mathrm{V}, 9^{\circ}$ texto.

${ }^{10}$ Immanuel Kant, op. cit.

"Werner Wolff, What is Psychology, 1947, Nueva York, Grune \& Stratton, primeros capítulos. tiene repetidamente la primacía de lo aprendido, al mismo tiempo que se dan una y otra vez ejemplos de la importancia de lo innato.

En historia y etnología nos topamos con el caso del difusionismo, que sigue siendo rechazado en muchas partes con la misma tenacidad con la cual se rechazaba a priori la idea de Schliemann de que Troya había existido: era más sencillo suponer que se trataba de una fantasía mítica. Hay muchas razones para rechazar las abundantes exageraciones a que ha dado lugar la libertad aparentemente ilimitada de establecer comparaciones como las engendradas por ciertos difusionistas de las primeras épocas, pero debería evitarse negar la gran verdad en que se funda toda esa corriente de pensamiento histórico, a saber, que es lícito imaginar una relación causal (aunque más no sea como hipótesis de trabajo) allí donde las semejanzas formales o funcionales llaman la atención del investigador.

Para concluir, dos precisiones metodológicas. Ya he adelantado la primera al mencionar a Descartes: el principio de la hipótesis más ardua no es un 'criterio de verdad', es decir, no garantiza que dicha hipótesis sea la correcta; sólo sienta una prioridad científica; es el principio de la laboriosidad contra el de la comodidad. Si alguna vez la NASA juzgó 
NOTAS

digno de interés rastrear toda posible prueba de la existencia de seres de otros planetas, ello no implica que las 'pruebas' de Erich von Däniken tengan algún valor. "Si nos conformamos con la "leyenda de la llegada de extraterrestres', por interesante y atractiva que parezca, resulta superflua cualquier otra investigación tendiente a solucionar los enigmas." 12 En el mismo sentido, la homeopatía y la acupuntura son las 'hipótesis más difíciles' en la medicina. Otro tanto dígase de la posibilidad de lograr una traducción enteramente automática.

Segunda precisión: ninguna teoría es a priori un caso de hipótesis metodológicamente preferible; al emplear el comparativo ('más difícil') se indica ya que tiene que haber al menos dos hipótesis para decidir comparativamente cuál de ellas no puede, por las razones metodológicas antedichas, abandonarse sin investigar. Incluso es necesario incluir en este grupo las teorías que, por reduccionistas, han sido blanco predilecto de las críticas en la historia de la ciencia: cuando Durkheim reduce lo religioso a categorías so-

${ }_{12}$ Peter Hertel/Gisela Klügel-Hertel, Ungelöste Rätsel alter Erdkarten, 1988, Gotha, Hermann Haack-GeographischKartographische Anstalt, p. 56, refiriéndose a los enigmas de ciertos mapas antiguos. ciales, ${ }^{13}$ cuando ya en la Antigüedad (con Lucrecio) la religión fue reducida al fenómeno del miedo, ${ }^{14}$ cuando la lingüística recibe un tratamiento logicista y la lógica un tratamiento psicologicista (este último rechazado con razón a partir de Frege), se trata en todos los casos de las hipótesis respectivamente más trabajosas.

Sería ocioso comentar los textos citados, cuyo lenguaje sumamente claro los convierte en ilustraciones ideales, aunque parciales, de ese criterio que debe cumplir toda hipótesis científica que ingrese a la palestra compitiendo con otra: la prioridad epistemológica del esfuerzo sobre la comodidad.

${ }^{13}$ Émile Durkheim, Les formes élémentaires de la vie religieuse, 1968 , París, PUF, p 13, Introd., II.

${ }^{14} \mathrm{Y}$ también en la actualidad, cfr. Bertrand Russell, Why I Am Not a Christian, 1977, Londres, Allen \& Unwin, p. 25. 